\title{
Preorthodontic enhancement of fragile phenotype periodontium
}

\author{
C. Goubron'1, M. Le Gall2,3,4, C. Philip-Alliez²,3, V. Monnet-Corti2,5 \\ 1 Former hospital-university assistant in dentistry, private practice of dentistry in La Ciotat \\ 2 Public Assistance Hospitals in Marseille (Hôpital de la Timone-AP-HM, Dentistry Division)-School \\ of Dentistry, Aix-Marseille University \\ ${ }^{3}$ Lecturers of universities-Hospital practitioner \\ ${ }^{4}$ Private practice of orthodontics in Aubagne \\ ${ }_{5}$ Professor in Universities. Hospital practitioner. Periodontology. President of the French Society of \\ Dentistry and oral Implantology
}

\begin{abstract}
Periodontology and orthodontics are two closely related odonatological disciplines, both of which affect the periodontium of our patients. If in most cases orthodontics have no adverse effect on the periodontium, in case of fragile (weak?) phenotype periodontium (low height or lake of keratinized tissue, thin bone tables, fenestrations or bone dehiscence) orthodontic treatment can, depending on the movements performed, cause or aggravate periodontal recessions that are unsightly and painful for the patient and compromise the results. Through a clinical case we will see how to prevent and treat these cases to make orthodontic treatment possible and maintain its results over time.
\end{abstract}

\section{KEYWORDS}

Orthodontics, periodontics, fragile phenotype periodontium, gingival recession, periodontal plastic surgery

Gingival recession is defined by the American Academy of Periodontology $y^{1,2}$ as the upward movement of the gum at the cementoenamel junction. It affects a large proportion of the population, leading to unattractive smiles and sensitive teeth and gums, which hurt during brushing and chewing. Their etiology is related to a range of predisposing factors (anatomical factors such as bone dehiscence, bone windows, fine bone tables, absence or low height of keratinized tissue, deposits, traction or shallow vestibules) and triggering factors (traumatic brushing, noncarious cervical lesions, inflammation, biological space violation, occlusal trauma, extraction, and orthodontic displacements ${ }^{12,21,24}$ ) acting together. Faced with a weak-phenotyped periodontium, some orthodontic movements such as the coronolingual version of the mandibular incisors, coronovestibular version, the vestibular translation, the radiculovestibular torque movements, the mesiodistal movements of a tooth in a narrow toothless zone and transverse expansion may cause periodontal lesions ${ }^{20}$. When a

Address for correspondence:

Cyril Goubron - 8 Rue Montaigne - 13012 Marseille

E-mail: cyrilgoubron@gmail.com

This is an Open Access article distributed under the terms of the Creative Commons Attribution License (http://creativecommons.org/licenses/by/4.0), which permits unrestricted use, distribution, and reproduction in any medium, provided the original work is properly cited. 
patient has periodontal subsidence, orthodontic treatment may worsen these retreats, due in part to the work done to the teeth and from wear and tear relating to the fitting and wearing of an orthodontic device. The strength- ening of a fragile periodontium, as we will see in the following case, makes it possible to decrease the risk of causing or aggravating recessions during and after orthodontic treatment in a sustainable manner.

\section{CASE REPORT}

A 37-year-old patient was referred to the periodontology office by her orthodontist for a periodontal evaluation and investigations before orthodontic treatment. The patient is a nonsmoker and only has a medical history of hypothyroidism treated with $125 \mathrm{mg} /$ day of levothyroxine ${ }^{\circledR}$.

The orthodontic examination reveals an Angle Class-I malocclusion of the canine and molar with anterior mandibular encumbrance following the evolution of the wisdom teeth and a slight anterior overhang with lingual dysfunction (Fig. 1).

The line of the smile is average (Class-III parodontia ${ }^{6}$ ) when smiling normally and very high (Class-I "parodontia" 16) when the smile is forced, the patient therefore realizes that the parodontia and the esthetics of her normal smile (Fig. 2a) and forced smile (Fig. 2b) must be taken into account during the establishment of a treatment plan (processing).

In the periodontal examination, we note the presence of a Maynard and Wilson Class-III paradontia ${ }^{18}$, associated with Miller Class-I gingival recessions 19, with cervical bleeding, not caused by abfraction, and covered with deposits; an incomplete absence of plaque and tartar and an absence of periodontal pockets and gingival inflammation (Fig. 3). The radiological examination reveals no osseous pathology.
The diagnosis of Miller Class-I recessions ${ }^{19}$ of $3 \mathrm{~mm}$ in height on average on teeth $13,23,44,43,42,41,31$, 32, 33, and 34 (Table I) is made with a predisposing factor of fine bone tables. The triggering factor is traumatic brushing (hard toothbrush and supported horizontal motion), aggravated by a malocclusion and previous mandibular crowding). The treatment objectives will be (a) the removal of the triggering factor and (b) fixing these recessions and the strengthening of the periodontium.

The treatment plan proposed for the patient should be the etiological treatment of recessions by reeducating the brushing method with a 2-month reassessment of its proper application and then periodontal radicular recovery, plastic surgery with mucosal grafts associated with flaps. Indeed, mucosal transplantation with a coronally positioned flap is the technique that allows for the best clinical outcomes in the treatment of unitary recessions with or without loss of traction?, and is still the one that has the highest probability of being the best treatment for multiple recessions ${ }^{13}$. Because of the limited amount of connective tissue available, it was decided that three surgeries be carried out: first covering 13 and 23; then $32,31,41,42$, and 43; and finally 33,34 , and 44. 

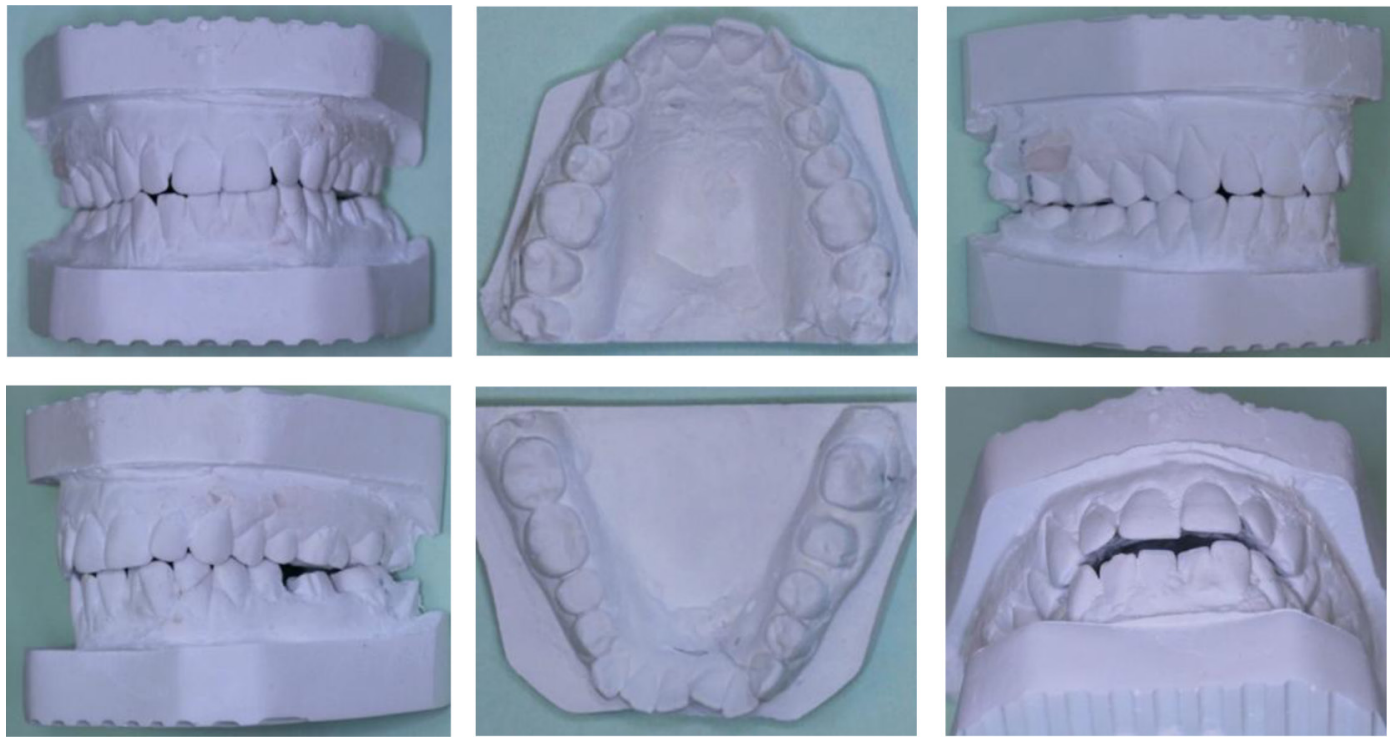

Figure 1

Study models.
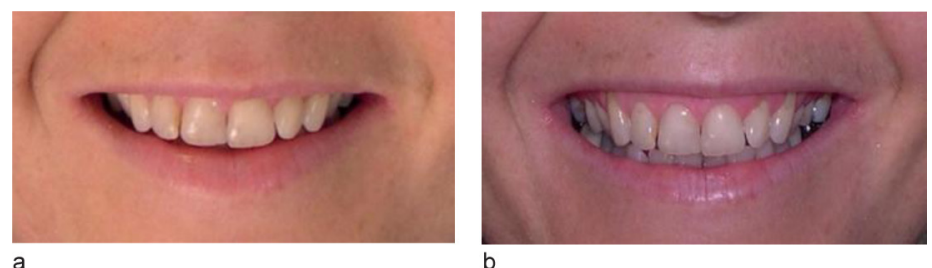

Figure 2

(a) normal smile. (b) forced smile.
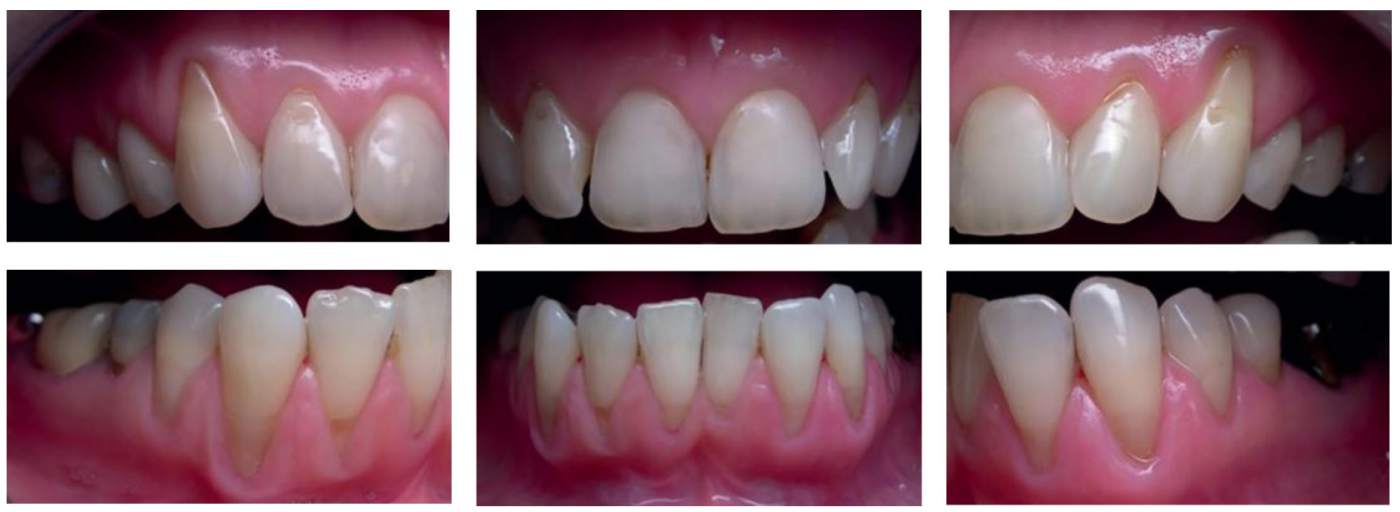

Figure 3

Initial review. 
Table I: Initial actions.

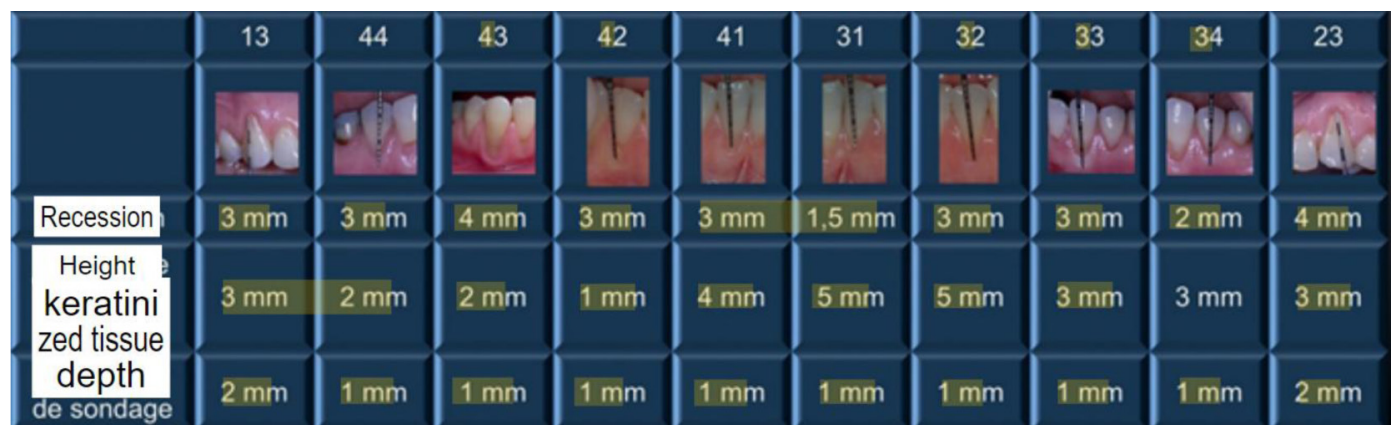

\section{SURGICAL TREATMENTS}

\section{Mucosal Sample (Fig. 4)}

All samples were assembled at the palatal level (which provides more connective tissue than the tuberosity) between the mesial aspect of the first molar and the distal aspect of the lateral incisor, at $3 \mathrm{~mm}$ of the tooth collar. The Bruno ${ }^{6}$ technique modified by Hürzeler and Weng ${ }^{15}$, with a single incision is used to minimize the risk of tissue necrosis and to improve the patient's comfort. In addition, a ther- moformed palate plate is placed at the end of the procedure

\section{Mucosal graft associated with a coronary displacement of 13 and 23 (Figs. 5 and 6)}

Initially, the composites covering the recession are removed and the exposed cementing is covered (Fig. 5a and 6a) to make it biocompatible with the mucosal graft.
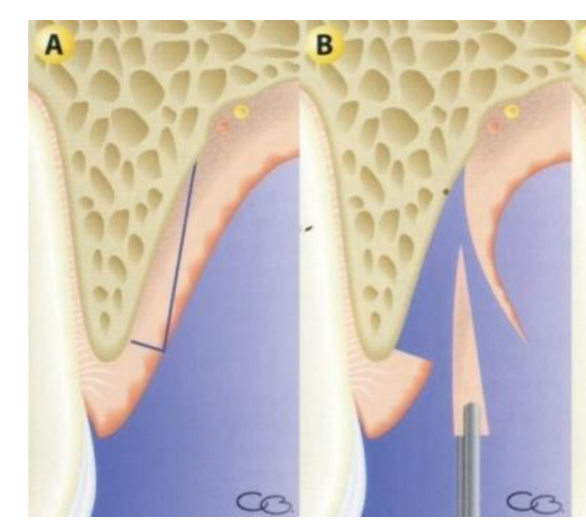

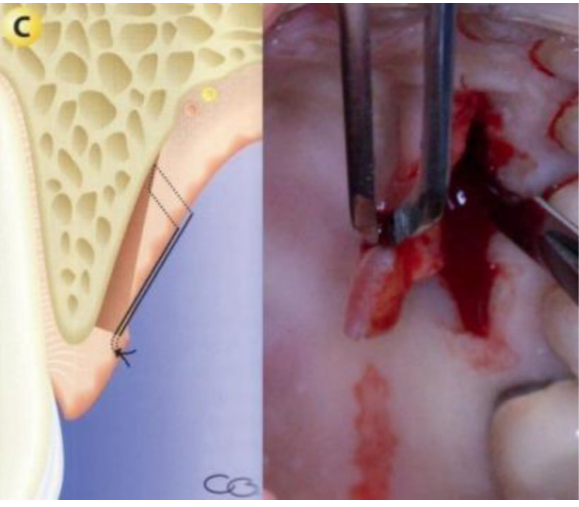

Figure 4

Bruno ${ }^{5}$ technical mucosal collection. (a) First incision perpendicular to the long axis of the teeth and second incision parallel to the long axis of the teeth (b) Graft detachment.

(c) Wound closure. 


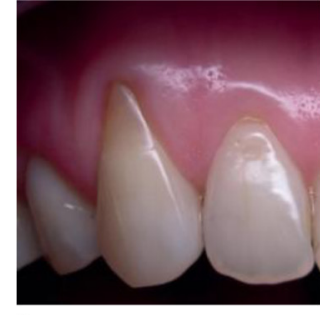

a

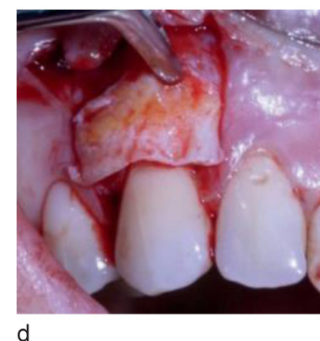

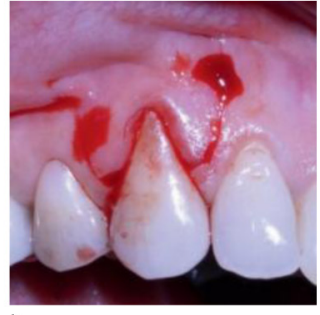

b

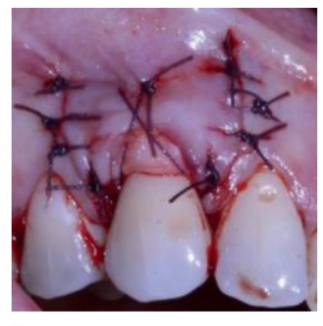

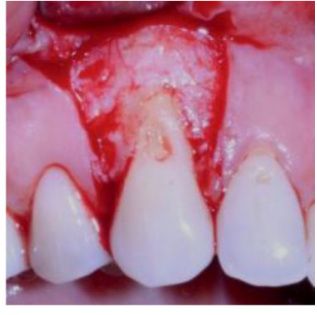

C

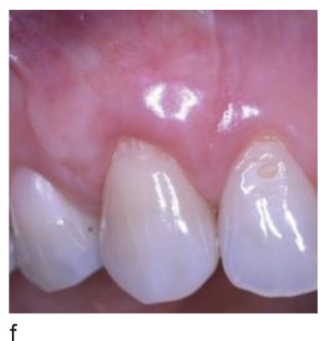

Figure 5

Buried mucosal graft with a coronary displacement of 13. (a) Preoperative. (b) Incisions.

(c) dissection. (d) Implementation of the mucosal graft. (e) Sutures. (f) 60 days after surgery.

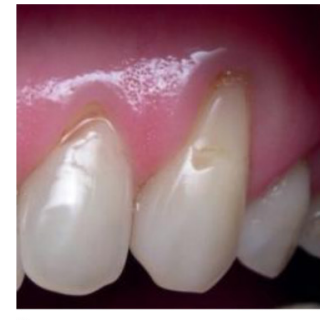

a

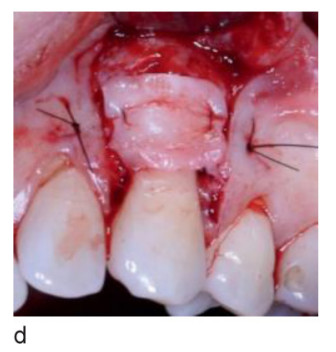

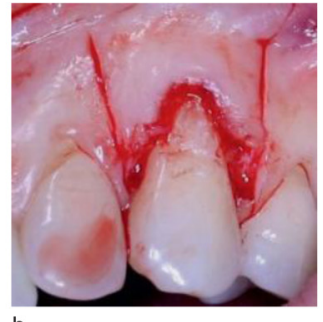

b

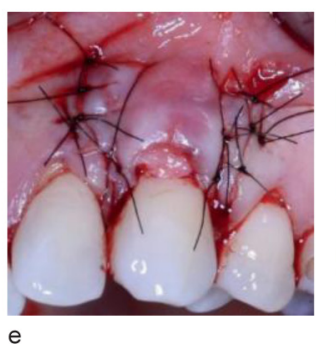

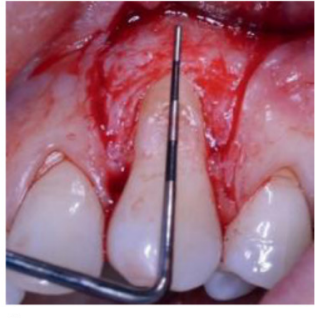

c

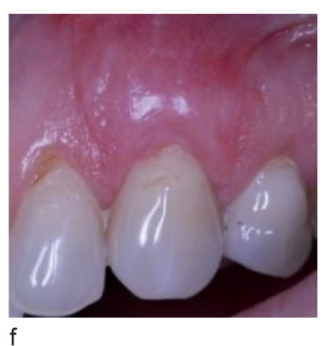

Figure 6

Buried mucosal graft with a coronary displacement of 23. (a) Preoperative. (b) Incisions.

(c) Dissection. (d) Implementation of the mucosal graft. (e) Sutures. (f) 60 days after surgery. 
The height of the recession is moved from the top of the papillae along the tooth. From this point forward, the buds are drawn and connected by an intrasulcal incision on the tooth to be treated with slight oblique stress-relieving incisions on either side that continue beyond the mucogingival line (Fig. 5b and 6b).

A partial-thickness flap is used until sufficient laxity is obtained for its coronary motion (Figs. 5c and 6c). The papillae are de-epithelialized with a thin blade (MJK N¹) or thin scissors.

The connective graft is positioned to completely cover the recession and sutured at the flap's margins by horizontal mattress sutures (Figs. $5 d$ and $6 d$ ). The flap is then moved to cover the graft and closed with simple suture points attached to the papillae.

Cross or noncross hanging sutures may be added to best place the graft and flap on the radicular surface (Fig. 5e and 6e).

\section{Bruno $^{16}$ technical graft $32,31,41$, 42, 43 (Fig. 7)}

The composites are remodeled to recreate a new anatomical cementoenamel junction, the exposed root is covered (Fig. 7a and 7b).

An intrasulcal incision is made on the teeth to be treated. In the interdental spaces, another incision is made by a horizontal incision at the base of the papillae. An envelope is then produced by a partial apical-thickness dissection, this dissection continues laterally on either side of the teeth while preserving the integrity of the distal papillae (Fig. 7c).

The mucosal graft is then placed into this envelope and attached to fully cover the recessions (Fig. 7d).

The flap is then re-applied and sutured by simple points at the base of the papillae. Suspended points can be made to perfect the immobilization of the graft and the flap (Fig. 7). The mucosal graft is left in place and will be re-introduced

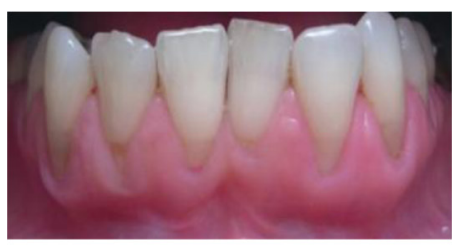

a

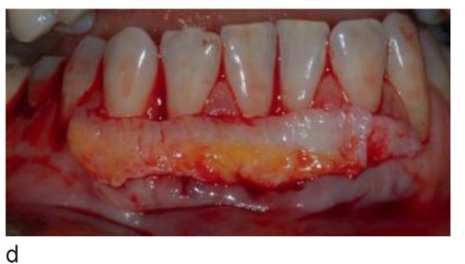

d

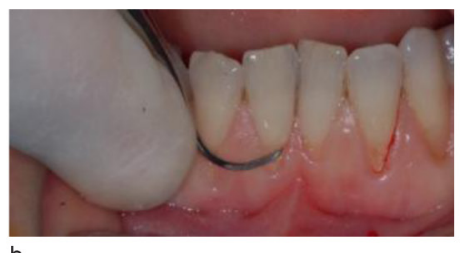

b

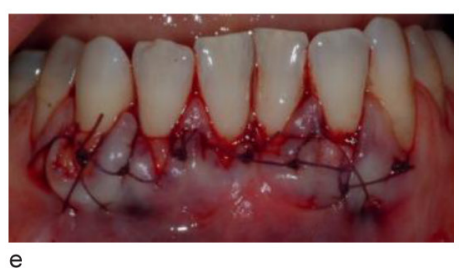

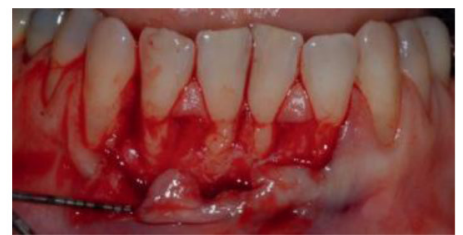

c

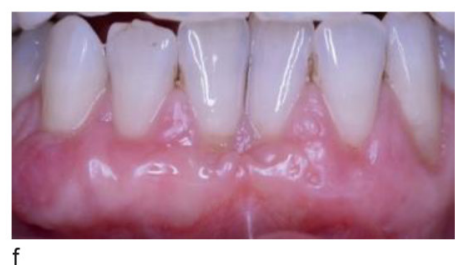

Figure 7

Bruno $^{16}$ technically buried the mucosal graft 43, 42, 41, 31, 32. (a) Preoperative. (b) Radicular surfacing. (c) Dissection. (d) Placement of the connective graft. (e) Sutures.

(f) 60 days after surgery. 
in a later procedure (Fig. 7f). The lack of discharge improves the graft vascularization and makes it optimal as the flap does not cover it at the root surface.

\section{Zucchelli and De Sanctis graft ${ }^{26}$ of 33 and 34 (Fig. 8)}

This technique consists of producing a flap without any fluid discharge with papillary rotation allowing its coronal positioning. The composites are then remodeled and the cement is covered (Fig. 8a).

The largest recessions are the center of rotation of the flap and the starting point of the incision paths here on the 33. The height of the recession is marked out on either side of the tooth to determine a point; the oblique incision at the base of the papillae begins at this point to return to the base of the recession of the adjacent tooth. The same principle is applied on the other teeth to be treated (Fig. 8b). An intrasulcal incision links these papillary incisions together and continues to one tooth on either side of the treatment area (Fig. 8c). The first part of the flap is dissected in partial thickness to the line connecting the bases of each recession, then continues with a total-thickness detachment to the mucogingival line, and then a fine partial-thickness dissection over the muscle planes that alleviate any flap tension (Fig. 8d).

The attaching graft is placed so as to coat the exposed and sutured root on the inner aspect of the flap. The flap is coronally pulled and sutured to the level of each papilla by simple points. A periosteal point at the bottom of the vestibule isolates the operating site from possible muscle tractions (Fig. 8e).
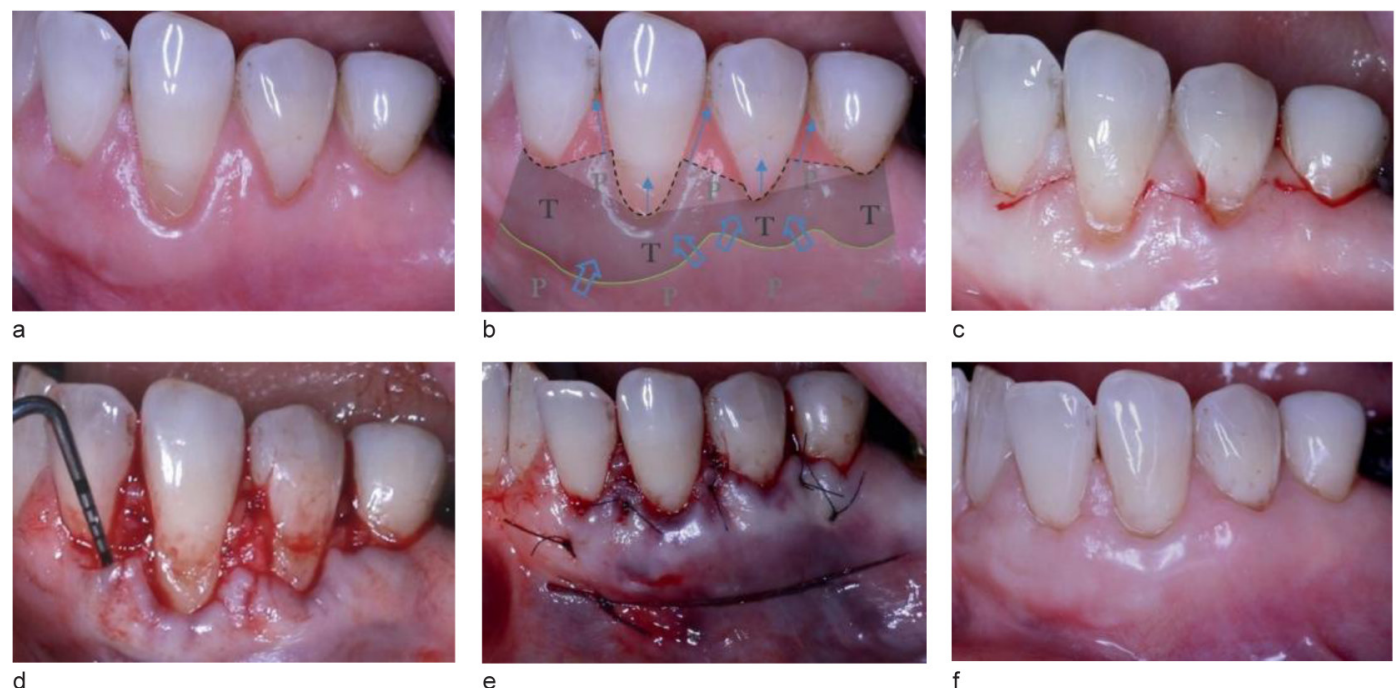

Figure 8

Buried mucosal graft associated with papillary rotation (Zucchelli and De Sanctis26 of 33,34). (a) Preoperative. (b) Incision patterns and technical principles. (c) Papillary incisions. (d) Partial dissection. (e) Sutures. (f) 60 days after surgery. 


\section{Bruno technical graft modified out of 44 (Fig. 9).}

The composites are remodeled and the cement is covered (Fig. 9a).

The intrasulcal incision is made on the tooth to be treated and continues onto the distal and mesial papillae (Fig. 9b). A partial-thickness dissection is made to create an envelope around the recession; then the graft is attached so that it fully covers the recession (Fig. 9c). It is attached together with the papillae by single points and the whole is sutured with periosteal sutures around the tooth (Fig. 9d).

\section{Postoperative care}

Precautions are illustrated (paracetamol $1 \mathrm{~g})$ and oral rinsing ( $\mathrm{CHX} 0.2 \%)$ are to be administered three times per day starting the day after the procedure. The brushing of the surgical area is prohibited until the 10-day points are removed and replaced by the local application of a $0.2 \%$ chlorhexidine gel. The brushing will be repeated with a postoperative toothbrush 6.5/100 for 7 days and continued with a surgical toothbrush 15/100. In the case of bleeding from the palatal site, the patient must a rinse out the oral cavity immediately (Dicynone ${ }^{\circledR} 250 \mathrm{mg} / 2 \mathrm{~mL}$ injectable), diluted in a half a glass of water for $10 \mathrm{~min}$ and swallowed.

\section{Results (Table II) \\ (Fig. 5f, 6f, 7f, 8f, 9e, 10, 11, 12)}

Final results can be measured after 6 months $s^{4,14}$.
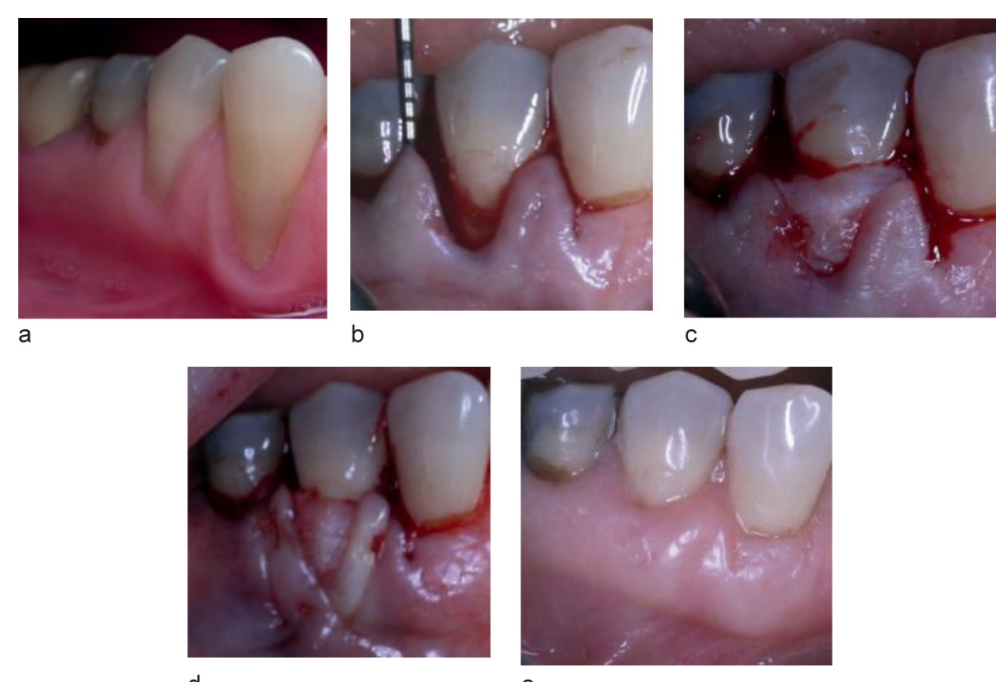

d

e

Figure 9

Bruno's modified technical buried mucosal graft 44. (a) preoperative. (b) incisions.

(c) Implementation of the mucosal graft. (d) sutures. (e) 60 days after surgery. 

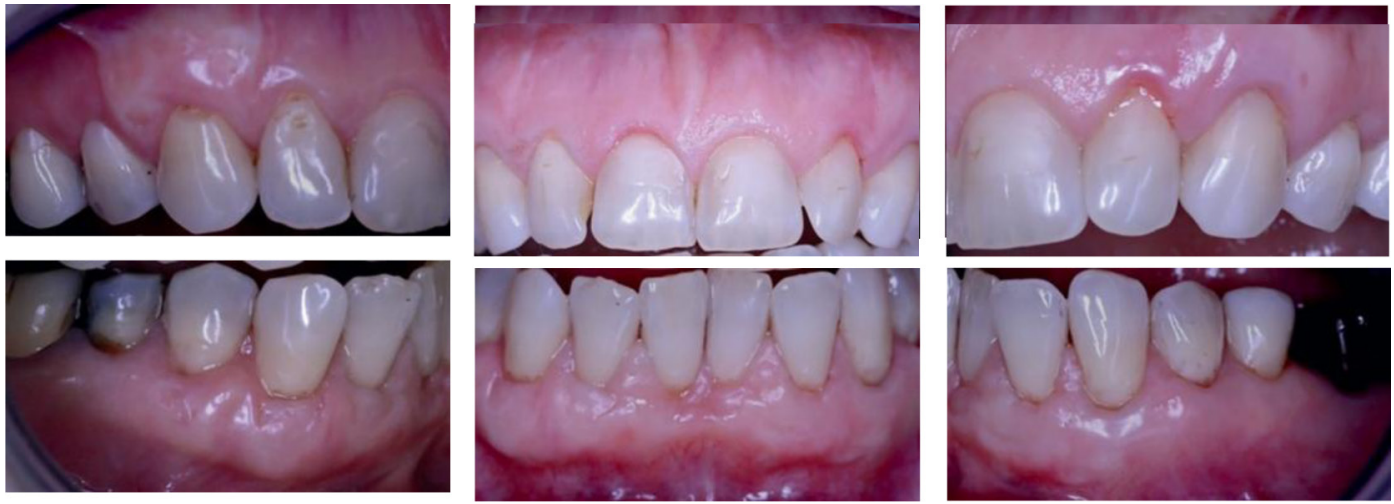

Figure 10

60 days after surgery.

Table II: Results 60 days after surgery.

\begin{tabular}{|c|c|c|c|c|c|c|c|c|c|c|}
\hline & 13 & 44 & 43 & 42 & 41 & 31 & 32 & 33 & 34 & 23 \\
\hline$=D^{0}$ & $3 \mathrm{~mm}$ & $3 \mathrm{~mm}$ & $4 \mathrm{~mm}$ & $3 \mathrm{~mm}$ & $3 \mathrm{~mm}$ & $1,5 \mathrm{~mm}$ & $3 \mathrm{~mm}$ & $3 \mathrm{~mm}$ & $2 \mathrm{~mm}$ & $4 \mathrm{~mm}$ \\
\hline SION 60 & $0,3 \mathrm{~mm}$ & $2 \mathrm{~mm}$ & $2 \mathrm{~mm}$ & $1 \mathrm{~mm}$ & $4 \mathrm{~mm}$ & $5 \mathrm{~mm}$ & $5 \mathrm{~mm}$ & $3 \mathrm{~mm}$ & $3 \mathrm{~mm}$ & $0,2 \mathrm{~mm}$ \\
\hline $\begin{array}{l}\text { RECOVERY } \\
\%\end{array}$ & $90 \%$ & $100 \%$ & $100 \%$ & $100 \%$ & $100 \%$ & $100 \%$ & $100 \%$ & $100 \%$ & $100 \%$ & $95 \%$ \\
\hline
\end{tabular}
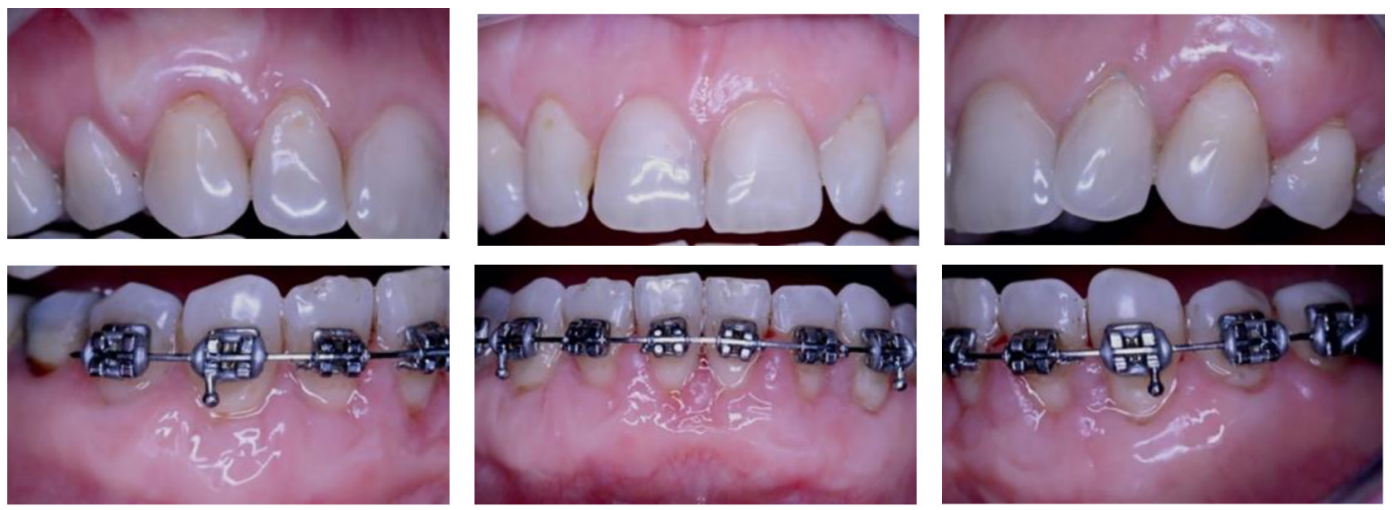

Figure 11

1 year after surgery. 

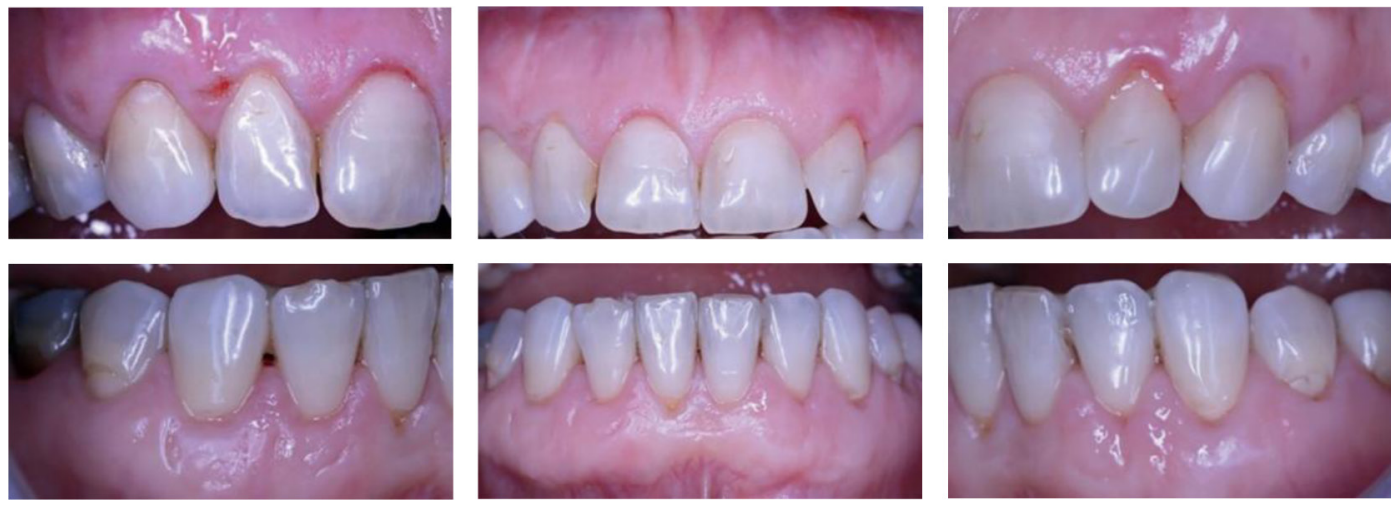

Figure 12

3 years after surgery

A complete recovery of all the mandibular recessions was obtained, with a strengthening of the periodontium (increase in height and thickness of the keratinized tissue). At the maxillarylevel a recovery of $90 \%$ was obtained on the 13 and $95 \%$ on the 23 with a reinforcement of the periodontium.

\section{DISCUSSION}

Orthodontic treatment can be a catalyst for the onset of periodontal recessions or aggravate pre-existing recessions. The risks depend on the volume of the gum and the types of orthodontic movements performed.

The vestibulolingual thickness of the attached gum appears to be a greater risk than the height in causing gingival recessions and loss of attachment in inflammatory sites during orthodontic treatments ${ }^{25}$. Some authors have shown that a narrow keratinized gum band seems capable of supporting orthodontic movements 9,10 . For others, there is a close correlation between decreased attached gum height and the percentage of gingival recession, especially in mandibular incisors where they have $\leq 1 \mathrm{~mm}$ of keratinized gum $^{22}$. The presence of a minimum of attached gums is necessary to maintain periodontal health during orthodontic treatments.

In vestibular movements of the incisors, if there is no inflammation, or apical displacement of the marginal gum without loss of attachment is observed. On the other hand, if inflammation is present, Wennström et al. ${ }^{24}$ show a loss of attachment. Similarly, the formation of bone dehiscence during movement often results in a reces$\operatorname{sion}^{3,9,11,21,24}$.

Linguistic movements are not risky when gums are fastened; However, in its absence, it is the riskiest situation, $27 \%$ patients will experience a recession, according to Maynard ${ }^{17}$. In this case, the increase in soft tissue will instead be achieved after orthodontic treatment ${ }^{23}$. 
Mesiodistal movements pose a risk when the tooth is moved to a tooth-like area with a decreased vestibulolingual dimension, especially because the ratio of attached gum to the displaced tooth is low.

During vertical grading movements, Castelli et al. ${ }^{8}$ measured bone thicknesses clinically, by history-taking, and radiologically using a cone-beam scan in a prospective 3-year study with 50 patients and evaluated the behavior of the periodontal phenotype in mandibular incisors. Patients with a fragile phenotype (fine and jagged periodontium) suffered greater bone loss than those with a flat and thick periodontium (0.11 $\mathrm{mm}$ versus 0.07 ).

Orthodontic treatment may cause gingival recessions on its own but may also damage the periodontium that may later lead to recessions caused by bacterial infection and/or trauma.

Periodontal plastic surgery, when implemented, strengthens the periodontium and prevents recessions. There are diverse careful surgical strategies accessible to us. The decision will rely upon the quantity of recessions to be prepared in that area and the professional's control of these systems.
For unit recessions, with or without interproximal loss of attachment, Cairo et al. ${ }^{7}$ concluded in a meta-analysis of 53 randomized trial articles involving 1,574 patients and 1,744 recessions that coronally displaced flaps associated with connective tissue graft provided the best results. Regarding the treatment of multiple recessions, Graziani et al. ${ }^{13}$ conclude that the flap positioned coronally with rotated papillae (Zucchelli and De Sanctis technique) associated with a buried connective graft and the tunnel connective graft produce the best full recovery rate.

In the presence of cervical wear lesions, the coronally positioned flapbased root covering technique associated with a connective graft has the best full recovery rate $160 \%$ at 6 months versus $36 \%$ if the flap is coronally placed $)^{10}$.

Composites that often cover these lesions should then be removed and reshaped prior to surgery to recreate the cementoenamel junction. The creation of these composites preoperatively avoids the use of incisions that may damage the grafted tissue and provide better access to the apical limits, which are supragingival and can be easily cleaned.

\section{CONCLUSION}

Preorthodontic periodontal testing by the orthodontist themselves or a periodontist is essential to prevent the risk of bone loss and recession. Depending on the case and the expected movement, the periodontist will intervene before or after treatment to correct gingival recessions. In all cases of a fragile periodontium, regular periodontal monitoring during orthodontic treatment is required: gingival inflammation, orthodontic brushing, can be either too aggressive to the gum or not aggressive enough, which can lead to iatrogenic plaque accumulation.

Conflict of interest: The authors declare no conflicts of interest. 


\section{REFERENCES}

1. American Academy of Periodontology. Glossary of periodontal terms. J Periodontol 1992;63 (special issue).

2. American Academy of Periodontology. Consensus report. Mucogingival deformities and conditions around teeth, 1999 International Workshop for a Classification of Periodontal Diseases and Conditions. Ann Periodontol 1999;4:101.

3. Batenhorst KF, Bowers GM, William JE. Tissue changes resulting from facial tipping and extrusion of incisors in monkeys. J Periodontol 1974;45:660-668.

4. Borghetti A, Gardella J. Thick gingival autograft for the coverage of gingival recession: a clinical evaluation. Int J Periodontics Restorative Dent 1990;10:216-229.

5. Borghetti A, Monnet-CortiV. Les techniques chirurgicales avancées, fig 12.9 in Chirurgie plastique parodontale et péri-implantaire, 3e edition. JPIO 2017;12:213- 233.

6. Bruno JF. Technique de greffe conjonctive assurant le recouvrement de dénudations radiculaires étendues. Rev Int ParodontDent Rest 1994;14:127-137.

7. Cairo $F$, Nieri M, Pagliaro U. Efficacy of periodontal plastic surgery procedures in the treatment of localized facial gingival recessions. A systematic review. J Clin Periodontol 2014; 41 (suppl. 15): S44-S62.

8. Castelli A, Le Gall M, Monnet-Corti V. Comportement du parodonte au cours du nivellement des incisives mandibulaires : précautions à prendre. Orthod Fr 2016;87:99-102.

9. Coatoam G, Behrents R, Bissada N. The width of keratinized gingiva during orthodontic treatment. Its significance and impact on periodontal states. J Periodontol 1981;52:307-313.

10. Cortellini $P$, et al. Does placement of connective tissue graft improve the outcomes of coronally advanced flap for coverage of single gingival recessions in upper anterior teeth? A multi-centre randomized double blind, clinical trial. J Clin Periodontol 2009;36:68-79.

11. Dorfman HS. Mucogingival changes resulting from mandibular incisor tooth movement. Am J Orthod 1978;74:286-297.

12. Foushee DG, Moriarty JD, Simpson DM. Effects of mandibular orthognatic treatment on mucogingival tissues. J Periodontol 1985;56:727-733.

13. Graziani Z, et al. Efficacy of periodontal plastic procedures in the treatment of multiple gingival recessions. J Clin Periodontol 2014;41 (suppl. 15): S63-S76.

14. Harris RJ. Connective tissue grafts combined with either double pedicle grafts or coronally positioned pedicle grafts: results of 266 consecutively treated defects in 200 patients. Int J Periodontics Restorative Dent 2002a;22:463-471.

15. Hürzeler $M B$, Weng $D$. Technique d'incision unique pour prélèvement de tissu conjonctif sous-épithélial aupalais. RevIntParodontDentRest 1999;19:279-287.

16. Liébart MF, et al. Smile line and periodontium visibility. Periodont Pract Today 2004;1:17-25.

17. Maynard JG. Mucogingival considerations for the adolescent patient. In: Nevins M, Mellonig JT (eds). Periodontal therapy: clinical approaches and evidence of success. Chicago: Quintessence Publishing Co, 1998:291-303.

18. Maynard JG, Wilson RD. Diagnosis and management of mucogingival problems in children. Dent Clin North Am 1980;24:683-703.

19. Miller PD. A classification of marginal tissue recession. 
20. Monnet-Corti V, Borghetti A. Physiologie-Pathologie et examen clinique du complexe muco-gingival. In : Chirurgie plastique parodontale et péri-implantaire, $3^{e}$ edition. JPIO 2017;2:35-71.

21. Steiner GG, Pearson JK, Ainamo J. Changes of the marginal periodontium as a result of labial tooth move- ment in monkeys. J Periodontol 1981;52:314-320.

22. Stoner JE, Mazdyasna S. Gingival recession in the lower incisor region of 15 years old subjects. J Periodontol 1980;51:74-76.

23. Wennström JL. Mucogingival considerations in orthodontic treatment. Seminars in Orthodontics 1996;2: 46- 54.

24. Wennström J, Lindhe J, Sinclair F, Thilande RB. Someperiodontal tissue reactions to orthodontic tooth movement in monkeys. J Clin Periodontol 1987;14:121- 129.

25. Zachrisson BU. Orthodontics and periodontics 1998. In: Lindhe J, Karring T, Lang NP (eds). Clinical periodontology and implant dentistry. 3rd edition. Copenhagen: Munksgaard, 1998: 741-793.

26. Zucchelli G, De Sanctis M. Treatment of multiple reces- siontype defects in patients with esthetic demands. J Periodontol 2000;71:1506-1514.

27. Zucchelli G, et al. Non-carious cervical lesions asso- ciated with gingival recessions: a decision-making process. J Periodontol 2011;82:1713-1724. 